\title{
УГОЛОВНО-ПРАВОВЫЕ ПОСЛЕДСТВИЯ СОГЛАСИЯ ПОТЕРПЕВШЕГО НА ПРИЧИНЕНИЕ ВРЕДА
}

\section{CRIMINAL LEGAL CONSEQUENCES OF THE ACCEPTANCE OF THE VICTIM FOR HARM}

\section{Tereshchenko}

Summary. The article explores the features of the criminal law assessment of acts committed under the consent of the victim to harm. A distinction is made between pseudo-consent, forced consent and voluntary consent, the assessment of quasi-consent on the part of persons participating in sports to assess the harm to health during the competition or the training process. A broad understanding of the presumption of consent in the legislation of foreign countries is revealed, and private rules for establishing limits of criminal liability in such cases are proposed.

Keywords: crime, victim, consent, harm to health, negligence. $\mathbf{0}$ собенности взаимодействия между преступником и жертвой в обстановке совершения преступления - важный вопрос, являющийся предметом межотраслевого обсуждения. В данном контексте научно-исследовательский интерес представляют такая категории, как согласие на причинение вреда, и взаимосвязанные с нею термины, относящиеся к учету вины потерпевшего, его провокативному поведению, волеизъявлению относительно последовательности или результата совершаемых действий или же возможности осознания наступления общественно опасных последствий в виде вред жизни или здоровью. Категория «согласие» имеет лексическое значение «разрешение, утвердительный ответ» [1, с. 724]. Во взаимосвязи со словосочетанием «причинение вреда» мы получаем конструкцию, в которой для лица очевидно, что взаимодействие с людьми, животными или механизмами характеризуется травмоопасностью, но это лицо выражает непротиворечивое и ясное волеизъявление относительно участия в них. Частными случаями таких ситуаций можно назвать множественные спортивные коллизии (спарринг, командные тренировки), управление источниками повышенной опасности (гоночные соревнования), показательные или жанровые выступления (цирковые представления с участием животных и людей). Все перечисленные ситуации несут в себе потенциальную угрозу
Терещенко Владислав Сергеевич Соискатель, Санкт-Петербургский юридический институт (филиал) «Университет прокуратуры Российской Федерачии»; Начальник юридической группы, филиал ФАУ Министерства обороны Российской Федерации «Центральный спортивный клуб армии» (СKA, г. Санкт-Петербург) vladislavter@mail.ru

Аннотация. В статье исследованы особенности уголовно-правовой оценки деяний, совершенных в условиях согласия потерпевшего на причинение вреда. Проведено разграничение псевдосогласия, вынужденного согласия и добровольного согласия, дана оценка квази-согласию со стороны лиц, участвующих в проведении спортивных состязаний, на причинение вреда здоровью во время соревнований или тренировочного процесса. Выявлено расширительное понимание презумпции согласия в законодательстве зарубежных стран и предложены частные правила установления пределов уголовной ответственности в таких случаях.

Ключевые слова: преступление, потерпевший, согласие, вред здоровью, неосторожность.

жизни или здоровью их непосредственных участников; кроме того, в структуре правовых последствий, связанных с причинением вреда, имеются коллизии, разрешаемые законодательством разной отраслевой принадлежности. И даже в обстановке, характеризующей механизм совершения преступления, может быть выявлена негативная роль жертвы.

Так, в гражданском праве одним из критериев определения размера возмещения вреда становится учет вины потерпевшего (ст. 1083 ГК РФ, например, исключает возмещение вреда, возникшего вследствие умысла потерпевшего, и презюмирует уменьшение компенсации при его грубой неосторожности). Правовая природа деликтных обязательств в настоящее время подвергается переосмыслению [2], однако любой конфликт, урегулированный нормами права, должен включать анализ поведения его участников.

Далее, в криминологии взаимоотношения между преступником и жертвой получили оценку в части прогнозирования первичной и повторной виктимизации [3], а в ряде случаев - и относительно провокативных поведенческих актов, инициированных последней [4, с. 22-32]. В уголовно-процессуальном праве используется принцип диспозитивности, вследствие которого потер- 
певший от преступления может самостоятельно оценить необходимость обращения в правоохранительные органы с заявлением о возбуждении уголовного дела (по делам частного и частно-публичного обвинения); кроме того, согласие потерпевшего необходимо в случаях прекращения уголовного преследования по нереабилитирующим основаниям (например, в связи с применением судебного штрафа и др.). Конечно, предмет уголовно-процессуальных отношений включает только ретроспективный анализ события преступления [5], однако посткриминальное взаимодействие с потерпевшим во многих случаях задается интенсивностью преступных действий, глубиной страданий, причиненных ему в момент совершения преступления.

В уголовно-правовой доктрине, в свою очередь, особенности взаимодействия между виновным и жертвой исследованы на нескольких уровнях. Первый из них относится к добровольному отказу от преступления, который может быть мотивирован жалостью и осознанием возможности совершения оконченного преступления. Однако жалость к потерпевшему, по результатам специальных исследований, обусловливает добровольный отказ не более чем в 8-14\% случаев [6]. А обстановка, в которой принимается решение о добровольном отказе, не свидетельствует о нейтральном или положительном отношении потерпевшего к происходящему.

Второй уровень исследования указанной проблематики относится к посткриминальному взаимодействию, включающему оказание виновным медицинской и иной помощи потерпевшему, деятельное раскаяние, заглаживание причиненного вреда. В данном случае потерпевший так же сохраняет негативное отношение к событию преступления, но при этом - с учетом активного поведения виновного - соглашается с ним примириться или не настаивает на его строгом наказании (либо оно подлежит обязательному смягчению на основании ст. 62 УК РФ). По делам о преступлениях небольшой и средней тяжести суды достаточно часто практикуют освобождение от уголовной ответственности (например, в 2019 г. в связи с деятельным раскаянием были прекращены уголовные дела в отношении 11882 лиц, в связи с примирением с потерпевшим - в отношении 108662 лиц [7]).

Третий уровень познания взаимодействия между виновным и потерпевшим в обстановке события преступления относится к оценке потенциального согласия потерпевшего на совершение тех действий, которые влекут уголовную ответственность. На этом параметре следует остановиться более подробно.

Так, приоритетно необходимо отграничить ситуацию согласия от случаев, когда потерпевший не осознает характера и степени общественной опасности совершае- мых в отношении него действий, вследствие чего не оказывает сопротивления виновному. Спектр этих случаев достаточно широк и определяется малолетством, преклонным возрастом, болезнью, бессознательным состоянием. При таких обстоятельствах виновный использует беспомощное состояние жертвы, точно представляя, что им совершаются общественно опасные действия, и их можно характеризовать как псевдо-согласие, т.е. в действительности отсутствующее.

Далее, можно выделить вынужденное согласие, когда лицо осознает преступный характер совершаемых в отношении него действий и активно не сопротивляется их совершению, поскольку находится в зависимом положении. В таких случаях законодатель также презюмирует умышленный характер содеянного, а в ряде случаев устанавливает ответственность за сам факт поставления потерпевшего в условия потенциального причинения вреда. Например, из ч. 1 ст. 133 УК РФ следует, что понуждение к действиям сексуального характера является наказуемым независимо от того, реализовал ли виновный умысел, включающий их непосредственное совершение, или нет. Вынужденное согласие будет иметь место, если жертва понуждения не сопротивляется совершению полового акта или иных действий сексуального характера.

Определенные особенности возникают при совершении преступлений с формальным составом, когда потерпевшим признается лицо, в отношении которого действия, входящие в объективную сторону преступления, априори запрещены, либо когда оно выражает волеизъявление относительно участия в совершении действий, запрещенных уголовным законом. В ряде случаев аналогичная ситуация имеет место и при совершении преступлений с материальным составом. Например, при совершении преступления, предусмотренного ст. 134 УК РФ, виновный и потерпевший (потерпевшая) действуют по обоюдной доброй воле, однако в силу недостижения жертвой «возраста согласия» содеянное является наказуемым. Аналогично в составах преступлений, предусмотренных ст. ст. 151, 151.1, 150 и 151.2 (если способ вовлечения или склонения не связан с применением насилия или угроз), п. «В» ч. 4 ст. 228.1, п. «а» ч. 3 ст. 230, ч. 1 ст. 234, ч. 1 и ч. 2 ст. 234.1, 240.1, 242.1, 242.2 УК РФ, потерпевший не возражает против совершения тех действий, которые приводят или могут привести к причинению ему вреда.

Кроме того, в части преступлений с материальным составом потерпевший не возражает против совершения действий, входящих в объективную сторону преступления, не воспринимая их как общественно опасные, поскольку в условиях некриминального взаимодействия они таким свойством не обладают. Они могут представлять собой медицинские или иные услуги, иные формы 
взаимодействия между людьми. Так, деяния, предусмотренные ст. 109, ч. 1 и ч. 2 ст. 118, ст. 121, ст. 122, ч. 1 и ч. 2 ст. 123, ч. 2 ст. 235 , п. «В» ч. 2 ст. 238 , п. «б» ч. 2 ст. 238.1 УК РФ, совершаются при наличии согласия потерпевшего, а наступление общественно опасных последствий не является для него очевидным. Иными словами, до момента причинения вреда жизни или здоровью жертвы она не воспринимает криминальный характер деяния.

Особняком в этом перечне располагается коллизия, связанная с совершением убийства потерпевшего с его согласия. С одной стороны, потерпевший выражает четкое и недвусмысленное согласие на лишение его жизни. С другой, законодатель не считает данное обстоятельство условием для установления привилегированной нормы, по которой могла бы наступать уголовная ответственность и рассматривает мотив сострадания, которым руководствует виновный, только как обстоятельство, смягчающее наказание. Некоторые авторы предлагают дополнить главу 16 УК РФ соответствующим привилегированным составом [8], однако в данный момент эта инициатива не реализована. В иных случаях, когда мотив сострадания не установлен, даже наличие согласия потерпевшего на совершение тех действий, которые могут повлечь его смерть, не влечет за собой отказ от квалификации содеянного как убийства (в качестве хрестоматийного примера здесь можно привести дуэль, которая в отдаленный исторический период считалась относительно «легальным» или привилегированным видом убийства, но в современных условиях подобное отношение к этому явлению представляется изжитым).

Обращаясь к нормам Общей части УК РФ, можно заключить, что в определенных случаях причинение вреда потерпевшему с его согласия образует состав невиновного причинения вреда. Однако и здесь необходимо сделать некоторые оговорки. Во-первых, в ст. 28 УК РФ законодатель не установил параметров, относящихся к установлению согласия потерпевшего. Иными словами, о таковом можно судить, лишь исходя из той обстановки, которая определила взаимодействие между людьми в момент причинения одним из них вреда жизни или здоровью второго (например, в ходе тренировочного процесса, репетиции, игрового эпизода). Во-вторых, в положениях ст. 28 УК РФ обоснована перспектива признания деяния совершенного невиновно в тех случаях, когда субъект не мог и не должен был предвидеть наступления общественно опасных последствий, либо не мог их предотвратить вследствие несоответствия своих личных психофизиологических качеств экстремальным условиям или нервно-психическим перегрузкам. Иными словами, лицо не в состоянии принять адекватного решения, способствующего недопущению наступления общественно опасных последствий [9].
Еще один аспект, в котором уместно рассмотреть согласие потерпевшего на причинение вреда,- это различные контактные взаимодействия между людьми, в которые они вступают по собственной воле. При этом нужно разделить согласие на взаимодействие (например, спарринг, соревнования в контактных видах спорта). Применительно к участию в этом процессе можно говорить о презумпции согласия. Однако относительно последствий в виде травм, относящихся к различной степени тяжести, презумпция согласия отсутствует. Имеет место только информированность о потенциально возможном травмировании (например, вследствие болевого приема, игрового столкновения). В то же время, обстоятельства, в связи с которыми может быть причинен вред здоровью или даже жизни потерпевшего, не обязательно носят случайный характер (например, «фол последней надежды», представляющий собой умышленную остановку голевой атаки соперника в некоторых командных видах спорта; в правилах некоторых командных игр это признается неспортивным поведением, влечет наказание в момент игры). Кроме того, правила командных игр могут содержать понятие «дисквалифицирующий фол», каковым признается вопиющее неспортивное действие [10, с. 41]. Однако в ненормативных, по сути своей, актах, определяющих правила проведения спортивных мероприятий, не раскрывается понятие «вопиющего» нарушения, т.е. оно носит оценочный характер, а кроме того, не описываются его последствия, наступившие для здоровья жертвы. Из этого следует, что в сфере спортивных взаимодействий не получила осмысления причинная связь между допущенным нарушением правил и возможными последствиями, а равно не оценивается форма вины, при наличии которой было совершено нарушение.

Понятие «безопасный спорт» справедливо характеризуется исследователями как противоречивое [11]: причинение вреда здоровью спортсменов является частью тренировочного и соревновательного процесса. Аналогично можно как противоречивое охарактеризовать отношение ученых к оценке причинения спортивной травмы с точки зрения учения о субъективной стороне преступления. На данный момент в уголовно-правовой доктрине сформировались подходы, основанные на признании наличия признаков неосторожной вины [12] или же невиновного причинения вреда [13]; умышленная вина в условиях, когда вред здоровью причинен во время соревнований или тренировочного процесса, не считается возможной [14]. Причиной этого можно назвать именно презумпцию согласия потерпевшего на участие в этих действиях.

Поскольку уголовный закон не признает причинение вреда в условиях спортивных состязаний обстоятельством, исключающим преступность деяния, на практи- 
ке события, связанные с причинением вреда здоровью спортсменов, получают уголовно-правовую оценку как совершенные по неосторожности (и тем самым, если причиненный вред является легким или средней тяжести, уголовные дела не возбуждаются). Из этого можно заключить, что причинение вреда здоровью или жизни спортсмена в ходе тренировочного процесса или состязаний имеет место в отсутствии согласия потерпевшего и - при наличии признаков вины - должно квалифицироваться как преступление, совершенное по неосторожности (например, в ходе силового единоборства к потерпевшему был применен болевой прием, повлекший расстройство здоровья) или даже умышленно (например, на фоне спорного решения арбитра среди спортсменов возникла драка, в ходе которой были нанесены телесные повреждения). Иными словами, презумпция согласия потерпевшего на причинение вреда в сфере спортивных отношений не действует, а понимание им риска получения травмы можно охарактеризовать только как квази-согласие, не исключающее уголовной ответственности причинителя вреда.

Логично предположить, что постановка вопроса о согласии потерпевшего на причинение вреда объективно невозможна, когда оно обусловлено его индивидуальными особенностями (высокий болевой порог, т.е. нечувствительность к боли) или психическим заболеванием (в последнем случае у него может и вовсе отсутствовать способность выражать волеизъявление). Тем не менее, известны ситуации, когда граждане соглашаются принимать участие в инцидентах, связанных с применением в отношении них насилия или с поставлением в угрожающие жизни условия, руководствуясь корыстными побуждениями, участвуя в пари или же действуя под влиянием других лиц. Например, в настоящее время определенной популярностью пользуются так называемые «трэш-стримы» - трансляции в сети «Интернет», участники которых позволяют совершать различные насильственные и унизительные действия в отношении себя (так, в июне 2020 г. органами внутренних дел г. Брянска начата проверка в связи с появлением в социальных сетях видеороликов, содержащих записи издевательств над молодым мужчиной; было установлено, что он участвует в этом добровольно, трансляция ведется с его согласия [15]). В исследованиях по психиатрии и психологии такое состояние лица признается разновидностью социофобии (обсессивно-компульсивный синдром, расстройство аутистического спектра, посттравматический синдром) [16, с. 36], и его использование в целях развлечения или из иных низменных побуждений должно влечь за собой уголовно-правовую оценку независимо от фактического наступления последствий.

Обращаясь к зарубежному законодательству в части регулирования уголовно-правовых аспектов согласия потерпевшего, можно отметить следующие интересные подходы.

Например, в странах англосаксонской правовой семьи при проведении спортивных мероприятий презюмируется согласие потерпевшего на причинение вреда. Однако эта презумпция охватывает только осознание риска получения травмы при соблюдении соперником правил соревнования и не может «охватывать вред, который невозможно предвидеть» [17, Р. 7679] (иными словами, травмы, нанесенные вне игрового пространства, могут квалифицироваться на общих основаниях).

В ряде европейских стран в системе обстоятельств, исключающих преступность деяния, предусмотрено такое, как причинение вреда при осуществлении законной (легальной, разрешенной) деятельности. Такие предписания содержатся в уголовных кодексах Нидерландов (ст. 42), Франции (ст. 122-4), Швейцарии (ст. 32). Иными словами, причинение вреда здоровью во время занятий спортом охватывается содержанием таких норм и, по общему правилу, не влечет за собой уголовной ответственности. Однако такая привилегия априори не распространяется на случаи, когда имеет место нелегальное спортивное состязание, либо когда правила, установленные в определенном виде спорта, были нарушены.

Кроме того, в законодательстве некоторых европейских государств установлен усложненный механизм определения неосторожной формы вины. Так, §222 УК ФРГ в систему преступлений против жизни включает такое, как лишение жизни по небрежности. Оно не относится к убийствам и, подобно деяниям, предусмотренным ст. 109 УК РФ, охватывает возможные ситуации, возникающие во время тренировочного и соревновательного процесса. Дифференциация норм об уголовной ответственности за нанесение телесных повреждений в УК ФРГ близка к российской, что делает возможным применение положений о неосторожном причинение вреда здоровью при квалификации спортивного травматизма.

Достаточно интересно обратиться к ст. 44 УК Республики Сан-Марино, которая прямо предусматривает норму, освобождающую от уголовной ответственности лиц, которые при проведении спортивных состязаний своими действиями нанесли ущерб сопернику или иным лицам. Пределы применения этого обстоятельства, исключающего преступность деяния, прямо ограничены законным режимом проведения состязания или соревнования. Из этого можно заключить, что вред жизни и здоровью, причиненный во время спортивных игр, по законодательству этой страны ненаказуем. 
В заключение можно сделать вывод о том, что согласие потерпевшего на причинение ему вреда остается одним из малоизученных уголовно-правовых явлений и нуждается в дальнейшем научном осмыслении. Применительно к охране жизни и здоровья лиц, занимающихся спортом, требуется разграничение презумпции согласия на участие в спортивных и тренировочных мероприятиях, и осознания риска вероятности получения травмы. При этом в отсутствие признаков невиновного причинения вреда и проявления потерпевшим грубой неосторожности такие инциденты должны получать уголовно-правовую оценку.

\section{ЛИТЕРАТУРА}

1. Лопатин, В.В., Лопатина, Л. Е. Русский толковый словарь / В. В. Лопатин, Л. Е. Лопатина.— М.: Эксмо, 2007. — 1200 c.

2. Ц Цыганов, В.И., Демин, А. А. Причинение вреда и юридическая ответственность / В. И. Цыганов, А. А. Демин // Legal Concept. — 2018. — T. 17. — № 1.— C. 31-38.

3. Евсеев, А.В., Радимушкина, О. В. Криминологическая характеристика и тенденции криминальной виктимизации в Российской Федерации / А. В. Евсеев, О. В. Радимушкина// Виктимология.-2018. - № 1.- С. 13-24.

4. Сидоренко, Э. Л. Виктимологическая провокация в уголовном праве России / Э. Л. Сидоренко.— Ставрополь: Ставропольский государственный университет, 2005.- $126 \mathrm{c}$.

5. Лубин, А.Ф., Миловидова, М.А., Гончан, А. Н. Уголовно-процессуальные отношения: постановка проблемы и основная гипотеза / А. Ф. Лубин, М. А. Миловидова, А. Н. Гончан // Юридическая наука и практика. Вестник Нижегородской академии МВД России.— 2015.— № 1.—C. 124-129.

6. Решетников, А. Ю. Добровольный отказ от преступления: проблемы теории и практики / А. Ю. Решетников // Актуальные проблемы российского права. - 2017. - № 8.- С. 122-132.

7. Отчет о работе судов общей юрисдикции по рассмотрению уголовных дел по первой инстанции за 12 месяцев 2019 года: Форма № 1 // Судебный департамент при Верховном Суде РФ [электронный ресурс] — Режим доступа: URL: http://www.cdep.ru/index.php?id=5 (Дата 06ращения: 04.06.2020)

8. Горбатова, М.А., Щипанова, Н. И. Ответственность за убийство из сострадания: вопросы теории и практики / М. А. Горбатова, Н. И. Щипанова // Вестник Южно-Уральского университета.— 2019. - Т. 19. — № 3.— С. 22-27.

9. Бохан, А.П., Мясников, В.В. Невиновное причинение вреда или дорожно-транспортное преступление? / А.П. Бохан, В. В. Мясников // Юристъ-Правоведъ. - 2016. - № 2.- С. 46-51.

10. Официальные правила баскетбола: утв. Центральным бюро ФИБА. — Пекин: ФИБА, 2008. - 83 с.

11. Дидур, М.Д., Выходец, М.И., Хохлина, Н.К., Журавлева, А.И., Поляев, Б. А. Безопасный спорт? Реалии, понятийные и нормативные аспекты / М.Д. Дидур, М. И. Выходец, Н. К. Хохлина, А. И. Журавлева, Б. А. Поляев // Вестник Российского государственного медицинского университета. - 2017.— № 6. C. 19-22.

12. Алексеева, А. П. Насилие в спорте и его применение различными субъектами: криминологический анализ / А. П. Алексеева // Научный вестник Омской академии МВД России. — 2012. - № 4. - С. 14-17.

13. Бавсун, М.В., Векленко, В.В., Сараев, В.В. Перспективы уголовно-правовой охраны профессионального спорта в России / М.В. Бавсун, В.В. Векленко, В. В. Сараев // Журнал российского права.— 2011.— № 3.—- С. $15-25$.

14. Соктоев, 3.Б., Ринчинова, А.Р. Согласие лица на причинение вреда его жизни и здоровью / З.Б. Соктоев, А.Р. Ринчинова // Вестник Университета им. О.Е. Кутафина (МГЮА).— 2018. — № 12.—С. 121-129.

15. Полиция в Брянске занялась проверкой стримов с издевательствами над человеком // ИA «Медуза» [электронный ресурс] — Pежим доступа: URL: https:/meduza.io/feature/2020/06/03/politsiya-v-bryanske-zanyalas-proverkoy-strimov-s-izdevatelstvami-nad-chelovekom-ego-v-tom-chisle-horonili-zazhivopohozhe-on-uchastvuet-v-s-emkah-dobrovolno (Дата обращения: 04.06.2020)

16. Мосолов, С. Н. Обсессивно-компульсивное расстройство (диагностика, клиника, терапия): монография / С. Н. Мосолов. — М.: Бином, 2005.—56 с.

17. Palmer, C. The Sports Monograph / C. Palmer.— London: SSTO Publications, 2014.— 198 P. 